\title{
Inhaltsverzeichnis
}

\section{HAIDINGER, Alois}

Datieren mittelalterlicher Handschriften mittels ihrer Wasserzeichen

MarTínez, María Antonia Negrete; UlReich, Hermann

Verzierte Keramik der Mittleren und Späten Bronzezeit in Hoyas del

Castillo, Pajaroncillo (Cuenca), Spanien . . . . . . . . . . . . . . . . .

Herold, Hajnalka; Ulreich, Hermann

Dünnschliffuntersuchungen prähistorischer Keramik von Hoyas del Castillo, Pajaroncillo (Cuenca), Spanien . . . . . . . . . . . . . . .

Kislinger, Ewald; Metaxas, Susanne; Отt, Iris

Conventazzo (Torrenova/ME): Archäologie und Geschichte (FWF-Projekt $P$ 14997). Bericht über die Aktivitäten 2001-2003 . . . . . . . . .

de Bernardo Stempel, Patrizia

Nehalen(n)ia, das Salz und das Meer . . . . . . . . . . . . . . . . . 181

ÜNAL, Rahim Hüsseyin et al.

Arbeitsbericht zum Münzschatz von Beçin . . . . . . . . . . . . . .

Kowar, Helmut

Feldforschung einmal anders: Musikautomaten entdecken und dokumentieren . . . . . . . . . . . . . . . . . . . .

Tichy, Gunther

Technikfolgen-Abschätzung: Entscheidungshilfe in einer komplexen

Welt . . . . . . . . . . . . . . . . . . . . . 
